\title{
Aspectos Gerais da Democracia Participativa e a Ordem Democrática Nacional
}

\author{
General Aspects of Participatory Democracy and National Democratic Order
}

\section{HAMILTON CUNHA IRIBURE JÚNIOR}

Doutor e Mestre em Direito pela PUC/SP, Professor da Graduação e do Mestrado da Faculdade de Direito do Sul de Minas (FDSM), Membro do IBCCrim, Avaliador do INEP, Advogado.

Submissão: 14.02 .2014

Decisão Editorial: 31.10 .2014

Comunicação ao Autor: 31.10 .2014

RESUMO: Os direitos fundamentais são parâmetros que limitam a atuação estatal quando do trato com o indivíduo. São construídos, historicamente, a partir de um contexto de lutas e narrativas de dominações. Os pactos sociais registrados pelas Cartas Políticas democráticas inserem em seu bojo tais direitos, costumeiramente associados a certas garantias fundamentais. A partir desse objeto de estudo, o presente ensaio analisa algumas das principais características associadas à questão da interpretação da norma jurídica e os seus possíveis efeitos delimitadores quando se tratar da veiculação de um conteúdo de direito fundamental. Demonstra-se que tal conteúdo se associa ao fundamento republicano da dignidade da pessoa humana e a opção feita pelo Brasil por uma democracia deliberativa. Uma das conclusões esperadas é a de que a função do aplicador da norma é a de nortear a atividade interpretativa que ocorre a partir dos limites impostos pelos preceitos fundamentais advindos da ordem garantista constitucional. A partir dos quadrantes estabelecidos pela teoria da democracia deliberativa é que se constrói o entendimento acerca da igualdade material como um dos instrumentos para a inclusão social.

PALAVRAS-CHAVE: Direitos fundamentais; norma jurídica; democracia.

ABSTRACT: Fundamental rights are parameters that limit the performance of the state when dealing with the individual. They are constructed, historically, from a context of historical struggles and domination. Social pacts recorded by Letters democratic policies fall within it those rights customarily associated with certain fundamental guarantees. From this object of study, this essay examines some of the main characteristics associated to the issue of interpretation of the rule of law and its possible effects delimiters when dealing with the placement of a fundamental right content. It demonstrates that such content is associated with the foundation of republican dignity of the human person and the option taken by Brazil for a deliberative democracy. One of the conclusions expected is that the role of the enforcer rule is to guide the interpretive activity that occurs from the limits imposed by fundamental precepts arising garantista constitutional order. From the quadrants established by the theory of deliberative democracy is that it builds the understanding of material equality as an instrument for social inclusion. 
KEYWORDS: Fundamental rights; rule of law; democracy.

SUMÁRIO: Introdução; 1 Os direitos fundamentais em uma perspectiva democrática; 2 Um consenso mínimo ético; 3 A questão da dignidade humana em uma perspectiva histórica; 4 Aspectos da teoria constitucional de democracia deliberativa; Considerações finais; Referências.

\section{INTRODUÇÃOO}

A conquista dos direitos fundamentais, bem como da democracia, insurge como uma das maiores conquistas da moralidade política, em que os ideais que tiveram maior repercussão e destaque como valores basilares da civilização ocidental foram a liberdade, a igualdade, os direitos fundamentais e a democracia, que se apresentam, simultaneamente, como fundamentos de legitimidade e elementos estruturantes do Estado Democrático de Direito.

A partir da denominada virada kantiana ${ }^{1}$, verifica-se uma reaproximação entre ética e Direito, com o ressurgimento da razão prática, da fundamentação moral dos direitos fundamentais e do debate sobre a teoria da justiça, fundado em um imperativo categórico jurídico.

Fundamenta-se tal imperativo por meio da aplicação do movimento denominado neopositivista, como seu principal precursor Hans Kelsen, e mais recentemente a partir da denominada virada linguística proposta por Wittgenstein e com os pós-positivistas, cujo intuito é reatribuir valores morais às decisões jurídicas. Ensina Gustavo Binenbojim² que "a ideia de dignidade da pessoa humana, traduzida no postulado kantiano de que cada homem é um fim em si mesmo, eleva-se à condição de princípio jurídico, origem e fundamento de todos os direitos fundamentais".

Insurge com o movimento constitucionalista um desejo cada vez maior de aproximar o direito positivado aos valores e garantias fundamentais conquistadas ao longo dos anos, de forma a alcançar o ideal denominado democracia. Esta consiste em um projeto moral de autogoverno coletivo, que pressupõe cidadãos que sejam não apenas os destinatários, mas também os autores das normas gerais de conduta e das estruturas jurídico-políticas do Estado.

Nesse sentido, o referido autor destaca que "a democracia representa a projeção política da autonomia pública e privada dos cidadãos, alicerçada em um conjunto básico de direitos fundamentais" ${ }^{3}$.

Verifica-se que a própria regra da maioria apenas é moralmente justificável em um contexto no qual todos os membros são capacitados ativa e passi-

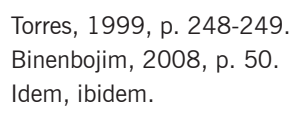


vamente, sendo tratados com igual respeito e consideração, tendo como pressuposto o direito fundamental à igualdade, transubstanciado, juridicamente, no princípio da maioria como técnica de deliberação coletiva ou plural.

A partir de tal análise, pode-se verificar a estreita relação existente entre direitos fundamentais e democracia, valendo afirmar que há uma relação de interdependência e reciprocidade. Conjugando-se esses dois elementos é que, segundo Gustavo Binenbojm, surge "o Estado democrático de direito, estruturado como conjunto de instituições jurídico-políticas erigidas sob o fundamento e para a finalidade de proteger e promover a dignidade da pessoa humana"4.

Da corrente denominada liberal do pensamento filosófico, o pensamento de John Rawls ${ }^{5}$ teve proeminência ao realçar o debate pós-positivista no campo da filosofia política e do Direito. Dessa forma, a noção kantiana de uso público da razão - que pressupõe uma comunidade de sujeitos livres e iguais - foi empregada para definir o que se convencionou denominar "elementos constitucionais essenciais", classificando-os em dois tipos, quais sejam:

i. os princípios fundamentais que especificam a estrutura geral do Estado e do processo político: as competências do Legislativo, do Executivo e do Judiciário; o alcance da regra da maioria; e

ii. os direitos e liberdades fundamentais e iguais de cidadania que as maiorias legislativas devem respeitar, tais como o direito ao voto e à participação na política, a liberdade de consciência, a liberdade de pensamento e de associação, assim como as garantias do império da lei.

Ao vislumbrar tal classificação, Rawls conclui que "os direitos e liberdades fundamentais têm caráter inalienável e um status especial em relação aos demais valores políticos ${ }^{\prime \prime}$, sustentando, ainda, que tais liberdades fundamentais não podem ser encaradas como absolutas, sendo que sua limitação ou negação somente se faz tendo em vista outras liberdades fundamentais, de modo a formar um sistema que seja coerente e que venha a garantir a igualdade aos indivíduos.

Inegável daí é a constatação de que a Carta Política deve assumir um viés liberal, adotar um padrão "Constituição-garantia", que especifica um procedimento político justo e incorpora as restrições que protegem as liberdades fundamentais, ao mesmo tempo em que asseguram a sua prioridade. Dessa natureza advém que tais diplomas albergam uma denominada ordem garantista, contemplando eficientes instrumentos destinados à proteção dos direitos fundamentais.

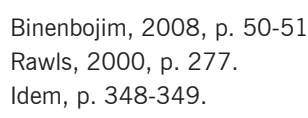




\section{OS DIREITOS FUNDAMENTAIS EM UMA PERSPECTIVA DEMOCRÁTICA}

À guisa de registro rasteiro acerca de um mínimo conteúdo que possa entender-se a democracia inerente a um sistema político garantista de direitos individuais, é adequado assegurá-la como um núcleo essencial desse sistema.

A democracia é o núcleo de um sistema de direitos fundamentais. Seu esquema de direitos fundamentais é todo ele deduzido logicamente do princípio discursivo, institucionalizado sob a forma do princípio democrático. Desta forma, os direitos fundamentais podem ser agrupados da seguinte forma: (1) direitos fundamentais que resultam da configuração política autônoma de direito à maior medida possível de iguais liberdades subjetivas de ação; esses direitos exigem como correlatos necessários; (2) direitos fundamentais que resultam da configuração politicamente autônoma do status de um membro numa associação voluntária de parceiros do direito; (3) direitos fundamentais que resultam imediatamente da possibilidade de postulação judicial de direitos e da configuração politicamente autônoma da proteção jurídica individual; (4) direitos fundamentais à participação, em igualdade de chances, em processos de formação da opinião e da vontade, nos quais os civis exercitam sua autonomia política e por meio dos quais eles criam direito legítimo; (5) direitos fundamentais a condições de vida garantidas social, técnica e ecologicamente, na medida em que isso for necessário para um aproveitamento, em igualdade de chances, dos direitos mencionados de (1) até $(4)^{7}$.

Dessa forma, relacionar a ordem constitucional com os ideais democráticos é missão que passa por importante etapa referente à criação da norma jurídica. Esta, ao ser elaborada, deve contemplar um padrão mínimo de mecanismos que possam garantir a efetividade prática dos direitos fundamentais.

Estudando essa questão, Ralws chama a atenção para a tarefa legislativa em estabelecer tal padrão, sempre associado à ideia de democracia, ao asseverar que "uma constituição desse tipo está em conformidade com a ideia tradicional de governo democrático, ao mesmo tempo em que abre um espaço para a instituição da revisão judicial" ${ }^{8}$.

Confirmando o que se apõe nesse raciocínio, Ronald Dworkin expõe a profunda relação existente entre direitos mínimos fundamentais e comandos democráticos estabelecidos por meio de um Pacto Social, sendo que "uma comunidade verdadeiramente democrática não apenas admite como pressupõe a salvaguarda de posições contramajoritárias (os direitos fundamentais), cuja força advém de princípios exigidos pela moralidade política" ${ }^{\prime \prime}$.

Habermans, 2010, p. 345.

Rawls, 2000, p. 277.

Dworkin, 1990, p. 324-346. 
A aplicação de princípios constitucionais democráticos soa como uma separação entre o Direito e a moral, tendo por base o positivismo jurídico, ou seja, parâmetros que expressam a norma de Direito em sua inteireza de efeitos e eficácia, assegurando àqueles a sua efetividade na ordem social.

Daí a importância de que os membros de uma determinada coletividade venham a atuar crendo que são regidos por um sistema de princípios que são moralmente relevantes, efetivamente aceitos, e não por regras que sejam forjadas a partir de apenas um compromisso político dissociado dos valores democráticos.

Assegura-se aos direitos fundamentais o núcleo de serem, essencialmente, direitos morais, reconhecidos no seio de uma comunidade política (comunidade de princípios) cujos integrantes são tratados com igual respeito e consideração. Desta forma, assegura-se a aplicação de um importante viés democrático - isonomia - ao Estado de Direito, prisma irretocável de boa parte das sociedades modernas que adotam a forma republicana de seus Estados.

Na esteira desse pensamento, pontua Gisele Cittadino ressaltando que

esta igualdade, que pressupõe os indivíduos como agentes morais independentes, exige que direitos fundamentais Ihes sejam atribuídos para que tenham a oportunidade de influenciar a vida política, realizar os seus projetos pessoais e assumir as responsabilidades pelas decisões que sua autonomia lhes assegura ${ }^{10}$.

O posicionamento aqui defendido infere que uma democracia apenas pode ser verdadeiramente considerada como uma premissa governamental caso os cidadãos sejam tratados de forma equânime, com igual respeito e consideração, logicamente, sendo-lhes assegurada a desigualação, admitida como uma forma de manter o equilíbrio e a justiça na aplicação da norma jurídica.

Os direitos fundamentais, portanto, podem ser entendidos como "condições democráticas", reconhecidos pela comunidade política sob a forma de princípios, sem os quais não há cidadania em sentido pleno, nem verdadeiro processo político deliberativo. Os direitos fundamentais tornam-se, antes, uma exigência mínima democrática, para, somente se necessário e a posterior, servirem de balizas limitadoras de outros direitos.

Referindo-se aos contornos do denominado ideal democrático do governo, exercido em nome do povo, ensina Gustavo Binenbojm que tal preceito seja atingido quando o princípio majoritário seja respeitado, de forma que, "nada obstante, o princípio majoritário não assegura o governo pelo povo senão quan-

10 Cittadino, 1999, p. 156. 
do todos os membros da comunidade são concebidos e igualmente respeitados como agentes morais independentes"11.

\section{UM CONSENSO MÍNIMO ÉTICO}

Importante destaque jusfilosófico quanto ao pensamento nuclear que envolve a relação entre os direitos fundamentais e democracia ocorre no movimento pós-positivista e se baseia na teoria do discurso e no procedimentalismo ético de Jurgen Habermas, por meio do qual se analisa a possibilidade de haver consensos morais materiais acerca de qual deve ser o conteúdo justo do Direito.

Em linha diversa do que se estabelece em Dworkin, Jurgen Habermas ${ }^{12}$ assenta que a formação democrática da vontade não subtrai a força legitimadora da "convergência preliminar em relação a convicções éticas consuetudinárias, mas sim de pressupostos comunicativos e procedimentos, os quais permitem que, durante o processo deliberativo, venham à tona os melhores argumentos".

Por intermédio dessa perspectiva, os direitos fundamentais não são produto de uma revelação transcendente - como o que ocorre na corrente jusnaturalista -, nem tampouco de princípios morais racionalmente endossados pelos cidadãos, mas consequência da decisão recíproca de cidadãos livres e iguais, que podem legitimamente regular suas vidas por intermédio do direito positivo.

Das relações apostas pela teoria do discurso e, ainda, tendo por base a democracia e os direitos fundamentais, Habermas assegura que

a ideia de autolegislação de cidadãos não pode, pois, ser deduzida da autolegislação moral de pessoas singulares. A autonomia tem que ser entendida de modo mais geral e neutro. Por isso introduzi um princípio do discurso, que é indiferente em relação à moral e ao Direito. Esse princípio deve assumir - pela via da institucionalização jurídica - a figura de um princípio da democracia, o qual passa a conferir força legitimadora ao processo de normatização. A ideia básica é a seguinte: o princípio da democracia resulta da interligação que existe entre o princípio do discurso e a forma jurídica. Eu vejo esse entrelaçamento como uma gênese lógica de direitos, a qual pode ser reconstruída passo a passo. Ela começa com a aplicação do princípio do discurso ao direito a liberdades subjetivas de ação em geral - constitutivo para a forma jurídica enquanto tal - e termina quando acontece a institucionalização jurídica de condições para um exercício discursivo da autonomia privada, inicialmente abstrata, com a forma jurídica. Por isso, o princípio da democracia só pode aparecer como núcleo de um sistema de direitos. A gênese lógica desses direitos forma um processo circular, no qual o código do direito e o mecanismo para a produção de direito legítimo, portanto o princípio da democracia, se constituem de modo co-originário. ${ }^{13}$

11 Binenbojim, 2008, p. 55.

12 Habermas, 2010, p. 345.

13 Idem, p. 158. 
Decorrência lógica dessa análise realizada por Habermas faz-se ao talante de levar a cabo, como essencial ao viés democrático de tais direitos, a substituição dos fundamentos moral e transcendental dos direitos individuais - próprios da tradição liberal - por um fundamento procedimental, extraído de sua teoria democrática. O princípio do discurso, elevado à condição de ideia-força da democracia, pressupõe uma igualdade entre os cidadãos, como pedra angular de um novo contrato social.

Paulo Ferreira da Cunha, em análise lapidar da questão, adverte que "a razão adquire o seu máximo expoente na comunicação plena, no pleno diálogo; logo, para tal, há que ter sujeitos iguais, que para isso darão as mãos numa sociedade com direitos fundamentais ${ }^{\prime 14}$, fazendo associar direitos fundamentais no entorno de valores mínimos de consenso social.

Ao se estabelecer um vértice no pórtico que une direitos fundamentais a um mínimo irredutível de valor ético, Habermas compatibiliza a soberania popular com os direitos humanos, tendo em vista que tais são admitidos como condições necessárias que tão somente possibilitam

o exercício da autonomia política; como condições possibilitadoras, eles não podem circunscrever a soberania do legislador, mesmo que estejam à sua disposição. Condições possibilitadoras não impõem limitações àquilo que constituem. ${ }^{15}$

Independentemente de qual aporte teórico se eleja para tal fundamentação, verificado está certo consenso hodierno acerca dos resultados aguardados quando se invoca a tutela dos direitos fundamentais em uma ordem democráti$\mathrm{ca}$, tendo, nestes, tanto um aspecto legitimador quanto elementos constitutivos do Estado Democrático de Direito, de onde se nota que suas influências vascularizam todas as instituições políticas e jurídicas sociais.

\section{A QUESTÃO DA DIGNIDADE HUMANA EM UMA PERSPECTIVA HISTÓRICA}

Uma imensidade de degraus foi palmilhada até que se fizesse constar em um Texto Constitucional um abrangente e eficiente sistema de garantias. Este mecanismo está arraigado no bojo da Carta Política de 1988, de onde emite um feixe de princípios orientadores da aplicabilidade das regras constantes do ordenamento jurídico nacional visando à harmonia do Estado Democrático de Direito.

A harmonização das regras processuais ao núcleo desse sistema de garantias $^{16}$ representa, na prática, a efetivação dos princípios constitucionais em todos os níveis em que se trava a relação entre Estado e indivíduo. Destarte,

14 Cunha, 1996, p. 433.

15 Habermas, 2010, p. 165

16 Ferrajoli, 2002, p. 683-687. 
cumpre-se a tão badalada adequação das regras constantes da norma jurídica infraconstitucional aos padrões normativos estabelecidos pela Constituição da República de 1988.

Esta Carta Política estabelece princípios e regras para a sistematização de qualquer atividade processual, repita-se, que deve pautar-se no sentido de que sejam respeitados os direitos fundamentais individuais ${ }^{17}$, sob o risco de ver-se anulada a prestação jurisdicional que não observar a mínima ordem garantista, núcleo do Estado Democrático de Direito.

Para tanto, a referida Carta Política, em seu frontispício, consagra como um dos fundamentos da República Federativa do Brasil a "dignidade da pessoa humana", preceito inerente ao ser humano, presente desde sua concepção, postulado inato e reconhecido como essência e fundamento da sociedade, sem o qual, aliás, não se justificaria ${ }^{18}$. Talvez a grande problemática esteja na conformação do seu conteúdo.

Em primeira via, para fins de análise do presente ensaio, destaca-se que invocar o fundamento constitucional da dignidade humana pressupõe reconhecer a pessoa como ser humano diferenciado dos demais seres devido a sua racionalidade e sociabilidade, devendo se desenvolver em meio apropriado para atender às suas necessidades.

É reconhecer-se na pessoa sua autodeterminação em relação ao Estado e a todos os outros seres. Daí a se enaltecer a dignidade humana como valor supremo que atrai o conteúdo de todos os direitos fundamentais do ser humano, desde o direito à vida ${ }^{19}$.

Conceituar em toda sua extensão o princípio da dignidade da pessoa humana é missão tormentosa na qual se incorre no risco de fomentá-la com expressões de conteúdo subjetivamente indeterminado. A etimologia da palavra dignidade tem origem no remoto latim dignus ${ }^{20}$, que era utilizado para referir-se a todo indivíduo que fazia jus à estima, era honrado e, por consequência, merecedor de importância no meio em que vivia.

Concebido como categoria espiritual, o vocábulo pessoa assume importância com o advento do Cristianismo ${ }^{21}$. Como herança de um dos insuperáveis mandamentos de Jesus Cristo, o vocábulo é utilizado para representar a ideia da unidade do ser humano ${ }^{22}$, este que passa a ser detentor de direitos fundamen-

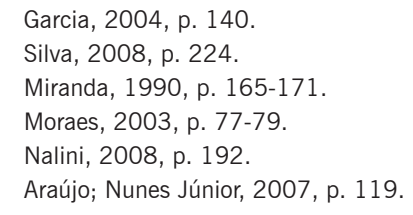


tais $^{23}$, criado à imagem e semelhança de Deus e que, em consequência desse pensamento, distanciava-se dos demais animais por possuir dignidade ${ }^{24}$. Dessa nova concepção do ser humano decorre o necessário reconhecimento de sua individualidade, contrastada com a necessidade social do Estado.

Da origem do princípio, assente em um valor de ordem moral, observa-se aos poucos a sua introdução nos ordenamentos constitucionais ${ }^{25}$, fazendo com que fosse aceito em uma dimensão jurídica como norma positivada, muito embora houvesse resistência em admiti-lo como um preceito estatal porque não cabia ao Estado imiscuir-se na vida do cidadão ${ }^{26}$.

Immanuel Kant vislumbrou o princípio como um imperativo categórico cujo valor na cultura dos povos beira a noção do absoluto. Defendia o filósofo que o ser humano tinha um valor peculiar, intrínseco, existente por si só, e, pelo fato de existir, já possuía dignidade. Asseverava, no entanto, que qualquer tentativa de excepcionar ou relativizar esse princípio seria infundada pela própria razão de ser deste, a qual se confundia com a existência humana.

Construiu-se, a partir de então, a noção de que o homem é um fim em si mesmo e não meio para os demais seres. Por conseguinte, é pessoa dotada de dignidade por sua racionalidade ${ }^{27}$. O ser humano nasce com o atributo da dignidade porque esta é parte essencial da personalidade e isso traduz, na prática, a obrigação genérica de respeito à liberdade individual, refletindo na aceitação da igualdade entre todos os integrantes da raça humana ${ }^{28}$.

Em síntese apertada, tem-se que do imperativo kantiano de que cada homem é um fim em si mesmo infere-se que a dignidade da pessoa humana é um valor único ${ }^{29}$. Conforme aduzido, a Carta Política de 1988 estatui a dignidade da pessoa humana como um dos fundamentos da República Federativa do Brasil $^{30}$, o centro de convergência de todos os direitos individuais.

Esse mandamento indica que a razão de ser do Estado é o ser humano, o indivíduo em toda a sua completude. Esse fato é comprovado também pela alusão da temática referente aos direitos e garantias fundamentais estar posicionada antes da que faz referência à organização do Estado no Texto Constitucional, permitindo inferir-se nesse sentido.

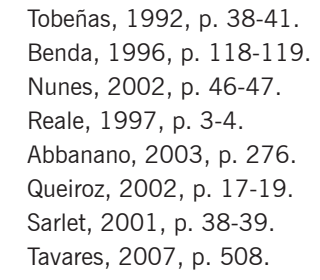


De antemão, cumpre destacar que o legislador constituinte na elaboração da Carta Política de 1988 fez uso de dois vocábulos distintos: direitos e garantias fundamentais, assegurando que os direitos possuem o caráter declaratório, ao passo que as garantias instrumentalizam tais direitos. Dessa forma, a inferir-se que os direitos fundamentais têm por fim a proteção da dignidade humana.

No Texto Constitucional de 1988, a positivação da dignidade da pessoa humana como um fundamento da República Federativa representa a elevação desse preceito à categoria de princípio maior do Estado brasileiro. Isso faz concluir que todos os demais direitos fundamentais lhe dão suporte e, por via oblíqua, são considerados como valores fundamentais para que então assegurem a dignidade do ser humano ${ }^{31}$.

Corolário lógico dessa posição topográfica da dignidade é que toda atuação do Poder Público tem que ser avaliada tendo em vista sempre o respeito ao indivíduo, sob o risco de ser transgredida a dignidade da pessoa humana. Nesse diapasão é que se infere que a pessoa é o caro valor da democracia, o núcleo das atenções do Estado, este que deve agir comprometido em sustentar, sob quaisquer penas, a integridade do indivíduo.

A afirmação dos direitos específicos do homem é a consequência do preceito da dignidade da pessoa humana, esta que é o coração dos direitos fundamentais. Situado no interior da Carta Política, esse princípio assume a função de fonte inspiradora positivada dos direitos basilares, atestando uma unidade de observância obrigatória ao sistema jurídico brasileiro ${ }^{32}$.

Estruturalmente, além de garantir a integração das normas jurídicas, o princípio da dignidade da pessoa humana assume duas outras importantes missões no ordenamento jurídico, quais sejam: orientar a interpretação constitucional na aplicabilidade das normas jurídicas e servir de fundamento para a sustentação do próprio ordenamento nacional ${ }^{33}$.

As normas de direito fundamental, por sua alta posição na ordem jurídica, são concebidas como balizas que vinculam a atuação do poder estatal e não podem ser modificadas por meio de processos legislativos comuns. Daí porque a interpretação e aplicação das demais normas constantes do ordenamento jurídico devem ser realizadas à luz do que estatuem as primeiras.

Do exposto aqui, nota-se que no Texto Constitucional a formulação do princípio da dignidade da pessoa humana como fundamento da República Fe-

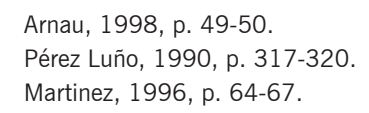


derativa do Brasil o faz ser apreendido com intocável magnitude dentro de seu limite intransponível, de natureza absoluta, portanto ${ }^{34}$.

No entanto, para a efetividade desse fundamento, há necessidade de que ele seja amparado por um sistema de direito com poder de coação, uma vez que o Estado tem por missão garantir a pessoa humana em sua inteireza, ressaltando-se sempre que a dignidade decorre da própria existência do ser humano, é congênita deste ${ }^{35}$.

Ao se admitir a dignidade da pessoa humana como princípio maior, absoluto para o qual todos os demais princípios devem observância irrestrita e invariável, roga-se que as regras e princípios de um ordenamento jurídico sejam elaborados e aplicados para garantir o valor da pessoa, sua unicidade, sua autodeterminação, sua afirmação frente ao Estado.

Entendendo pela inexistência de um princípio de valor absoluto na sistemática jurídica - valor que fosse supremo aos demais -, Ingo Sarlet preceitua no sentido de que a dignidade da pessoa humana seja desdobrada em duas porções: uma como regra e outra como princípio ${ }^{36}$.

A implicância disso está na razão de que o adequado enquadramento da modulação dos efeitos pretendidos por uma norma que expresse um valor de direito fundamental, frente ao preceito da dignidade humana, depende diretamente da vontade do intérprete da norma, de uma construção de sentido cultural e socialmente vinculada. Daí a admitir-se a ponderação da dignidade humana quando confrontada com os demais princípios, exigindo do intérprete a equalização e a extensão do sentido que deve prevalecer no caso concreto.

Por seu turno, e importante se faz o registro, a referência à natureza absoluta da dignidade da pessoa humana diz respeito à desnecessidade de haver qualquer inserção de cláusulas ou limitações em sua estrutura semântica. O que se afirma é que o referido princípio conta com uma série de fatores condicionantes que o faz anteceder todos os demais princípios e regras existentes no ordenamento jurídico, de forma que é possível observar em cada direito fundamental um traço do princípio da dignidade da pessoa humana.

Em linhas gerais, partilhando da relativização do conteúdo do princípio da dignidade da pessoa humana, ou sua limitabilidade, nota-se que, mesmo que inexistisse sua positivação na ordem jurídica nacional, ainda assim, seria possível apreender seu sentido devido sua natureza absoluta a grassar sobre as demais regras e princípios existentes no ordenamento. 


\title{
4 ASPECTOS DA TEORIA CONSTITUCIONAL DE DEMOCRACIA DELIBERATIVA
}

O desenvolvimento das teorias acerca dos direitos fundamentais e da democracia deliberativa alterou, sucessivamente na História da Civilização, a noção e a estrutura acerca do papel do Estado frente às liberdades individuais. A democracia deliberativa tem por uma de suas características mais importantes a de buscar conciliação entre as duas principais matrizes da teoria política moderna: a matriz político-liberal e a matriz democrática.

Claudio Pereira Souza Neto, ao analisar tais formulações, adverte que a tentativa de conciliar o liberalismo político com a democracia "não é uma constante nas reflexões sobre a política e o direito. [...] tanto no mundo dos fatos quanto no plano teórico, a soberania popular foi vista como uma ameaça a liberdade individual" ${ }^{37}$.

A matriz político-liberal tem como objetivo precípuo o de garantir a liberdade individual contra os eventuais abusos das autoridades estatais, onde, pode ser ressaltado, o liberalismo político como a garantia de direitos e das liberdades fundamentais. Nessa esteira, preleciona Norberto Bobbio que

\begin{abstract}
o liberalismo é uma doutrina do Estado limitado tanto com respeito aos seus poderes quanto às suas funções. A noção corrente que serve para representar o primeiro é Estado de direito; a noção corrente para representar o segundo é Estado mínimo. Embora o liberalismo conceba o Estado tanto como Estado de direito quanto como Estado mínimo, pode ocorrer um Estado de direito que não seja mínimo (por exemplo, o Estado social contemporâneo) e pode-se também conceber um Estado mínimo que não seja um Estado de direito (tal como, a respeito da esfera econômica, o Leviatã hobbesiano, que é ao mesmo tempo absoluto no mais pleno sentido da palavra e liberal em economia). ${ }^{38}$
\end{abstract}

O liberalismo político surge em um contexto em que se passa a propugnar pela limitação do Estado absolutista, caracterizado, fundamentalmente, pela centralização do poder político e pela monopolização da produção normativa. A democracia, por seu turno, preocupa-se não com a limitação do poder do Estado em favor das liberdades individuais, como ocorre no liberalismo, mas com a participação dos cidadãos no processo de tomada de decisões políticas. A vontade geral que é formada segundo preceitos da maioria

não é manifesta sob a forma de uma diktat imposto pela maioria a minoria, mas como resultado da influência mútua exercida pelos dois grupos, como resultado do embate de orientações políticas de suas vontades [...] De fato, todo o procedimento parlamentar, com sua técnica dialético-contraditória, baseada em discursos e réplicas, em argumentos e contra-argumentos, tende a chegar a um

37 Neto, 2006, p. 19.

38 Bobbio, 1994, p. 17. 
compromisso. Este é o verdadeiro significado do princípio da maioria na democracia real. ${ }^{39}$

A democracia deliberativa surge como forma de oposição às teorias de liberdade positiva e negativa, como forma de conciliar essas duas tradições em que está baseado o pensamento político moderno, e o faz de modo a sustentar a sua co-originalidade. Ensina Claudio Pereira de Souza Neto que "o estado de direito é entendido como condição de possibilidade da democracia. Sem liberdade de expressão, sem liberdade de pensamento, sem garantia do pluralismo político, não há democracia" ${ }^{\prime 40}$.

Estes são direitos fundamentais que exercem uma função imediata no processo deliberativo democrático. A noção de Estado de direito de que se vale a democracia deliberativa não se restringe à concepção liberal clássica, mas incorpora também as expectativas igualitárias que tradicionalmente têm sido vinculadas ao Estado social, onde esta igualdade material razoável é uma condição fundamental para a efetivação do Estado Democrático de Direito.

A democracia deliberativa pressupõe a igualdade de "possibilidades" de participação política, em que, sob o prisma formal, já foi consolidado como elemento inquestionável da estrutura institucional das democracias constitucionais. Nisso reside um grande viés crítico pelo fato de que a democracia tem se limitado ao reconhecimento, por meio da norma jurídica, de determinados parâmetros da feição democrática do Estado sem que tal reconhecimento legal tenha resultado na conformação de sociedades que sejam verdadeiramente democráticas.

A igualdade requerida pela democracia deliberativa, tal qual ocorre com a liberdade, também deve ser entendida como aquela necessária à instauração de um contexto propício para a interação cooperativa, com a distribuição justa dos recursos sociais. Só há deliberação sobre o bem comum se os participantes do processo político perceberem que, para além das diferenças, existe também um "nós", porque todos têm interesse na manutenção da estabilidade democrática.

A igualdade econômica razoável torna-se requisito fundamental para que, em um contexto de pluralismo, todos (grupos e indivíduos) se vejam motivados a cooperar no processo político democrático, compreendendo o outro com quem se dialoga como um parceiro na empreitada democrática e não como um inimigo que se busca eliminar.

39 Kelsen, 2000, p. 69-70

40 Neto, 2006, p. 57. 
Esse ponto de vista é compartilhado por Herman Heller ${ }^{41}$, que pontua como o Estado democrático se caracteriza por meio de uma unidade na multiplicidade de opiniões, sendo que "um certo grau de homogeneidade econômica deve ser garantido justamente para possibilitar essa unidade, já que é capaz de gerar uma consciência de sentimento do 'nós', uma vontade comunitária que se atualiza".

Há de se perceber que a linha caracterizadora da democracia não é o fato de haver uma discussão pública, mas, sim, a existência de um fundamento comum, de uma pauta mínima, adotada para a discussão social acerca dos valores que devem nortear a norma jurídica. Aduz-se aqui importante ensinamento de que "o remédio jurídico é aplicação da justiça (norma legal) com equidade, por ser essencialmente justo, mas não o justo segundo a norma legal, mas como um corretivo da justiça (norma legal) $)^{42 \prime \prime}$.

O modelo deliberativo implica não só a igualdade no que tange ao acesso ao procedimento democrático, mas, também, a igualdade quanto à capacidade de exercer a real influência na vida política, estando diretamente atrelada à ideia da capacidade igual de participar publicamente, com reais possibilidades de alterar os rumos decisórios do Estado.

Para Nancy Fraser"43, a inclusão exibe, "além da dimensão econômica, também uma dimensão cultural. Por isso as políticas inclusivas englobam não só redistribuição de recursos, mas também reconhecimento das diferenças". O reconhecimento em conjunto com a redistribuição é fundamental para instaurar um contexto de igualdade de capacidades para atuar em público. Em geral, enquanto a redistribuição é a solução adequada para as diferenças econômicas, o reconhecimento o é para as desigualdades de gênero e etnia.

A teoria constitucional de democracia deliberativa pretende "reconstruir" a normatividade constitucional em vigor, fornecendo-lhe "coerência" e "integridade". Desta forma, tal teoria é, ao mesmo tempo, descritiva e racionalizadora. Descritiva por entender que não seja mais viável, em face do fato de o pluralismo sustentar metafisicamente um sistema de princípios. Racionalizadora porque, ao buscar reconstruir as tradições políticas que de fato informam ao núcleo material da Constituição, consubstancia-se em princípios que são objeto de um "consenso" entre as diversas doutrinas abrangentes razoáveis.

Ao destaque da influência exercida pela real dimensão da democracia deliberativa, tem-se que

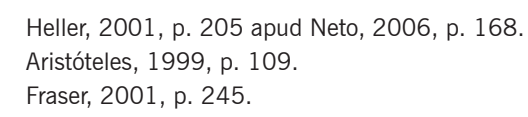


a compreensão da constituição só ganha sentido teórico-prático quando referida a uma situação constitucional concreta, historicamente existente num determinado país, i.e., uma teoria da constituição, se quiser ser de alguma utilidade para a metodologia geral do direito constitucional, deve revelar-se como uma teoria da constituição constitucionalmente adequada. ${ }^{44}$

Os elementos nucleares da democracia deliberativa surgem do processo de desenvolvimento de seus principais ideais, a começar pela "racional-normativa", que preponderou durante o constitucionalismo clássico, que tinha como preocupação principal estabelecer limites à atividade estatal, cuja formulação mais conhecida está presente na Declaração dos Direitos do Homem e do Cidadão.

A crise desse modelo clássico surge da relativização histórica do conteúdo constitucional e da elisão da justificação normativa, o que fez surgir inúmeras teorias da constituição, tanto de cunho formal-normativo quanto político-sociológico. A teoria formal-normativa de Kelsen apresenta-se como exemplo do corolário de sua cruzada para "purificar a ciência do Direito de qualquer reflexão de caráter sociológico, psicológico ou político"45.

O "reconstrutivismo" é a via seguida pela democracia deliberativa para superar o conflito entre a perspectiva descritiva e a prescritiva, cuja função é fornecer coerência ao sistema constitucional, e não de uma tentativa de identificar os princípios intrinsecamente válidos, como ocorria na antiga teoria racional-normativa, nem, tampouco, de uma descrição acrítica do direito constitucional positivo, como se dava na teoria positivista da constituição.

Em visão semelhante, ensina Ricardo Lobo Torres que "a constituição da democracia deliberativa pode ser entendida como uma constituição complexa, resultante da interação entre a constituição ideal e a constituição histórica" ${ }^{\prime 46}$.

Para a democracia deliberativa, a teoria constitucional não pode servir de álibi para que o intérprete deixe de aplicar os ditames constitucionais, considerando os fundamentos que alicerçam a República Federativa. A função do aplicador da norma, ao contrário, é a de apenas nortear a atividade interpretativa, a qual deve se dar a partir e nos limites do Texto Constitucional. É nesse contexto que se entende a democracia deliberativa.

Os fundamentos que servem de substrato para a democracia deliberativa indicam-na como um sistema aberto, cuja inferência se opera pelo repositório das tradições políticas que suportam o Estado Democrático de Direito. Ao compreendê-la dessa forma, se aceita a cooperação livre e isonômica de todos

4 Canotilho, 1994, p. 79 e 154.

45 Kelsen, 1998, p. 1/5.

46 Torres, 2002, p. 23/25. 
os indivíduos integrantes da sociedade, em uma determinada época de sua história e desenvolvimento.

Portanto, em contexto apertado, é plausível verificar-se que o núcleo da democracia deliberativa consiste na aferição de igualdade material, não só econômica, mas também a capacidade de atuar publicamente, fomentando-se a inclusão de todos por meio do reconhecimento das diferenças, o que gerou uma transformação da teoria constitucional, exigindo para sua legitimação uma reconstrução democrática, discursiva e coerente, a fim de se garantir a eficácia dos direitos fundamentais.

\section{CONSIDERACÕ̃ES FINAIS}

No pórtico do vertente trabalho, se analisam as decorrências de alguns aspectos de interpretação da norma jurídica, tendo em vista a questão dos direitos fundamentais tomados à luz do que se entende por democracia deliberativa. Tal pretensão tem se mostrado uma tarefa escarpada ao longo do desenvolvimento da civilização humana, tendo esse desafio fomentado uma profunda reflexão em várias linhas do pensamento jusfilosófico.

A importância desse debate aqui trazido se mostra atual no sentido de se notar que a mais alta Corte de Justiça brasileira tem se expressado com veemência nestes últimos tempos, no sentido de acolher teses garantidoras da aplicação de direitos fundamentais, em sentido amplo, alterando inclusive conceitos e naturezas jurídicas de institutos albergados na Carta Política vigente, ao mesmo tempo em que encontra, em certos momentos, grandes dificuldades em estabelecer o que seja, então, um patamar mínimo aceito para citados direitos.

Mostra-se, no presente ensaio, que essa tônica atravessa a história e desafia não somente o aplicador do Direito, como desperta grande interesse em outras áreas do conhecimento - como a filosofia - e da fé. O vértice de toda a discussão parece convergir para o indivíduo. A ele destinam-se a norma e seus efeitos. Como lidar com um Estado que transgride e avança os quadrantes de respeito ao indivíduo?

A resposta está na convenção coletiva que se estabelece dentro de um pacto social, concebido e plasmado em valores propostos na valorização e promoção de direitos fundamentais mínimos, associados a garantias que possam assegurá-los em caso de lesão ou ameaça.

Daí a se ressaltar a dignidade da pessoa humana como um fundamento republicano, pilastra central de todo o ordenamento jurídico e de onde se irradiam luzes para que sejam elaborados e aceitos princípios e normas de direito. Qualquer atividade estatal tem nesse preceito seu ponto de arranque e de 
chegada. Demonstra-se aqui que estabelecer os contornos desse mandamento fundamental torna-se o grande desafio para o aplicador da norma de direito.

Os direitos fundamentais são concebidos na órbita do valor da dignidade humana. Não poderia ser diferente. O Estado não pode agir sem limites e freios, seja qual for o seu campo de ação. Na questão específica da atividade de interpretação da norma de direito, cabe ao julgador sopesar valores fundamentais estampados na Carta Constitucional para efetivar o comando jurídico expresso através da norma a ser aplicada.

A Carta Política de 1988 albergou em seu conteúdo um feixe de princípios fundamentais, inspirados na altivez de propósitos que libertaram o ser humano de toda dominação e escravidão, ao longo de sua existência. Isso fez convergir para um modelo de sistema constitucional pautado em uma ordem garantidora de direitos individuais fundamentais, cravados nesse diploma que passe para a história como a Carta Política Cidadã.

Ainda que se tenha esse sistema garantidor constitucional, há que se ressaltar que a norma de direito, embora concebida por meio de um processo legislativo democrático, carece de um procedimento de aferição e modulação dos seus efeitos, tendo em vista o caso prático. Daí a importante e árdua tarefa do julgador, operador do direito, ator social responsável por dar fôlego de vida à, até então, letra da lei.

Ao aplicar o comando da norma de direito ao caso prático, o julgador pode fazer efetivar restrições a direitos fundamentais. Nesse segundo campo aqui avaliado, busca-se assentar algumas premissas essenciais para essa tarefa de interpretação da norma jurídica, tendo por base um sistema constitucional de direitos fundamentais.

Daí a se invocar a teoria constitucional da democracia deliberativa como um dos possíveis instrumentos hábeis para se aferir em que condições é que da atividade estatal possa se produzir resultados satisfatórios e justos, reduzindo-se os efeitos de uma exclusão social gerada constantemente por violação de direitos fundamentais.

No contexto de um determinado direito material, a efetividade da norma pode ser expressa por intermédio da isonomia e da paridade entre as partes, garantia de que a aplicação da norma pelo julgador depende tão somente do mérito jurídico das partes, sem haver conexões com diferenças que sejam alheias aos direitos individuais postos, estranhas ao que se analisa, portanto.

Ao se sustentar neste trabalho a ideia de invocar a democracia deliberativa como lastro seguro para provocar uma atividade interpretativa da norma jurídica com maior equidade, minimizando-se as violações a direitos fundamentais, quer-se que seja compreendido que os ideais da democracia deliberativa 
não fiquem em um plano abstrato, mas que sejam efetivamente uma realidade. A participação cívica na formação dos valores do Estado é a base para o acesso à justiça e para o combate das liberdades negativas.

Do aporte jusfilosófico aposto no vertente trabalho, resta claro que somente é possível atingir um nível de justiça na interpretação da norma de direito, se houver uma real compreensão do conteúdo expresso pela equidade. Uma das funções aguardadas do aplicador da norma é a de nortear sua atividade interpretativa à luz dos preceitos fundamentais advindos da ordem garantista constitucional.

A interpretação da norma deve abstrair conteúdos que sejam estranhos aos valores expressos pelos direitos fundamentais, cujo conteúdo central se faz pela dignidade da pessoa humana. E isso se faz possível somente se o aplicador da norma, operador do direito, eleger a equidade como valor caro à democracia, rumo inafastável por onde deve seguir a esteira da justiça.

\section{REFERÊNCIAS}

ABBAGNANO, Nicola. Dicionário de filosofia. Revisão da tradução e tradução dos novos textos: Ivone Castilho Benedetti. São Paulo: Martins Fontes, 2003.

ARAUJO, Luiz Alberto David; NUNES JÚNIOR, Vidal Serrano. Curso de direito constitucional. 11. ed. São Paulo: Saraiva, 2007.

ARNAU, Juan Andrés Muñoz. Los limites do los Derechos Fundamentales en el Derecho Constitucional Español. Pamplona: Editorial Aranzadi, 1998.

BENDA, Ernesto. Manual de Derecho Constitucional. Madri: Marcial Pons Ediciones Juridicas y Sociales, 1996.

BINENBOJIM, Gustavo. Uma teoria do direito administrativo: direitos fundamentais, democracia e constitucionalização. 2. ed. rev. e atual. Rio de Janeiro: Renovar, 2008.

BOBBIO, Norberto. Liberalismo e democracia. 6. ed. Trad.: Marco Aurélio Nogueira. São Paulo: Brasiliense, 1994.

CANOTILHO, José Joaquim Gomes. Constituição dirigente e vinculação do legislador: contributo para a compreensão das normas constitucionais programáticas. Coimbra: Coimbra, 1994.

CITTADINO, Gisele. Pluralismo, direito e justiça distributiva. Rio de Janeiro: Lumes Juris, 1999.

CUNHA, Paulo Ferreira. Constituição, direito e utopia: do jurídico-constitucional nas utopias políticas. Coimbra: Coimbra, 1996.

DWORKIN, Ronald. Equality, Democracy and Constitution: We the people in court. Alberta Law Review, 28, 1990. 
. O império do direito. Trad.: Jefferson Luiz Camargo. São Paulo: Martins Fontes, 1999.

FRASER, Nancy. Da redistribuição ao reconhecimento? Dilemas da justiça pós-socialista. In: SOUZA, Jessé (Org.). Democracia hoje: novos desafios para a teoria democrática contemporânea. Brasília: UnB, 2001.

GARCIA, Maria. Limites da ciência: a dignidade da pessoa humana - A ética da responsabilidade. São Paulo: Revista dos Tribunais, 2004.

HABERMAS, Jurgen. Direito e democracia: entre faticidade e validade. 2. ed. rev. Trad.: Flávio Beno Siebeneichler. Rio de Janeiro: Tempo Brasileiro, v. 1, 2010.

KELSEN, Hans. A democracia. Trad.: Ivone Castilho Benedetti et al. 2. ed. São Paulo: Martins Fontes, 2000.

. Teoria pura do direito. Trad.: João Batista Machado. 6. ed. São Paulo: Martins Fontes, 1998.

MARTINEZ, Miguel Angel Alegre. La dignidad de la persona como fundamento del ordenamiento constitucional español. León: Universidad de León, 1996.

MIRANDA, Jorge. Manual de direito constitucional. 4. ed. Coimbra: Coimbra, 1990.

MORAES, Maria Celina Bodin de. Danos à pessoa humana: uma leitura civil-constitucional dos danos morais. Rio de Janeiro: Renovar, 2003.

NALINI, José Renato. Duração razoável do processo e a dignidade da pessoa humana. In: MIRANDA, Jorge; SILVA, Marco Antonio Marques da (Coord.). Tratado Luso-Brasileiro da Dignidade Humana. São Paulo: Quartier Latin, 2008.

NETO, Claudio Pereira de Souza. Teoria constitucional e democracia deliberativa: um estudo sobre o papel do direito na garantia das condições para a cooperação na deliberação democrática. Rio de Janeiro: Renovar, 2006.

NUNES, Castro. Teoria e prática do Poder Judiciário. Rio de Janeiro: Forense, 1943.

PERELMAN, Chaim. Ética e direito. São Paulo: Martins Fontes, 1999.

PEREZ LUÑO, Antonio Enrique. Derechos humanos, Estado de Derecho y Constitucion. 3. ed. Madri: Tecnos, 1990.

PIOVESAN, Flávia. Direitos humanos e o direito constitucional internacional. São Paulo: Max Limonad, 1996.

QUEIROZ, Cristina M. Direitos fundamentais - Teoria Geral. Coimbra: Coimbra, 2002.

RAWLS, John. O liberalismo político. Trad.: Dinah de Abreu Azevedo. São Paulo: Ática, 2000.

REALE, Miguel. Lições preliminares de direito. 22. ed. São Paulo: Saraiva, 1995. 
SARLET, Ingo Wolfgang. Dignidade da pessoa humana e direitos fundamentais na Constituição Federal de 1988. Porto Alegre: Livraria do Advogado, 2001.

SILVA, Marco Antonio Marques da. Cidadania e democracia: instrumentos para a efetivação da dignidade humana. In: MIRANDA, Jorge; SILVA, Marco Antonio Marques da (Coord.). Tratado Luso-Brasileiro da Dignidade Humana. São Paulo: Quartier Latin, 2008.

TAVARES, André Ramos. Curso de direito constitucional. 5. ed. rev. atual. São Paulo: Saraiva, 2007.

TOBEÑAS, Jose Castán. Los derechos del hombre. 4. ed. Madrid: Reus, 1992.

TORRES, Ricardo Lobo. A cidadania multidimensional na era dos direitos. In: Teoria dos direitos fundamentais (obra coletiva). Rio de Janeiro: Renovar, 1999.

A constituição ideal dos direitos: o liberalismo igualitário na obra de Santiago Nino. In: MACEDO, Ubiratan Borges de (Org.). Avaliação crítica da proposta da democracia deliberativa. Rio de Janeiro: Círculo de Estudos do Liberalismo; Londrina: Edições Humanidades, 2002. 